\title{
Prevalence of Lactose Intolerance and its Association with Malnutrition in Children
}

\author{
Neel Kanth, Sejal Neel*, Ramchandani Santosh, Zainab Abbasi \\ Department of Pediatrics, Sindh Government Children Hospital, North Nazimabad, Karachi, Pakistan.
}

\begin{abstract}
Introduction: Lactose Intolerance is an important indicator of under nutrition, as studied in many setting. More than $60 \%$ especially in older school going children had a hypolactasia and half of them had Lactose intolerance. Another dimension of the problem could be lactose intolerance leading to underweight.
\end{abstract}

Objectives: 1 . To determine the prevalence of Lactose intolerance in 5-15 years of age group.

2. To determine the peak age group that is most susceptible to lactose intolerance in children of 05 years to 15 years of age.

3. To find out association of lactose intolerance with malnutrition.

Methodology: This is a cross sectional study design where a randomly selected 220 children of school going age were provided with lactose drink and their intolerance was assessed by $\mathrm{H} 2$ breath test. The child ingests a load of carbohydrate 2 gram $/ \mathrm{kg}$ maximum 50 gram and the breath is collected in sealed plastic containing and limited interval up 2 hour after ingestion. The hydrogen content of the gas can be easily measured and is reported in particle per min.(ppm) and that's how malabsorption of any lactose can be evaluated.

Results: Results of this study shows $31 \%$ percent prevalence in children, who had Lactose intolerance in-group of 220 asymptomatic children. In this study the highest number of Lactose Intolerance was found in oldest age group that is more than eleven years and $33 \%$ in lowest age group (less than 8 years of age).

The numbers of tolerant and intolerant children in normal height group were $73 \%$ and $27 \%$ respectively. Stunted group had $42 \%$ intolerant and $58 \%$ tolerant Children. But when tolerant group (Negative HBT) was observed the difference in stunted and normal height group children was statistically significant $(\mathrm{p}=0.034)$.

Difference in the number of intolerant children (Positive HBT) in stunted group and normal height group was not statistically significant. $25.9 \%$ were underweight, amongst them $37 \%$ were intolerant and $63 \%$ were tolerant, but on the other hand $74.1 \%$ normal weight children, whose weight was above the $80 \%$ of median, $28.8 \%$ were intolerant and $71.2 \%$ were tolerant. This also indicates that underweight children had more intolerance in comparison to normal weight children but this was not statistically significant $(\mathrm{p}=0.26)$.

Conclusion: It is possible that nutritional status may affect lactose absorption, so that lactose mal-absorbers may be less well nourished than lactose absorbers. We could not fully link up the lactose intolerance and under-nutrition, but we can recommend on the bases of finding in this research that whenever new policies of combating malnutrition were framed, use of milk in supplementation program should be used with caution.

Keywords: Lactose intolerance, Malnutrition, Hydrogen breathe test, Stunted, Underweight, Wasted.

\section{INTRODUCTION}

Lactose is a disaccharide composed of glucose and galactose. An enzyme, called Lactase, digests it. Those who loose this ability are known as lactose mal-absorbers and one who tends to acquire clinical symptoms after milk consumption are described as lactose intolerant. Lactose is obtained predominately from milk.

Lactose intolerance is a predominant indicator of under nutrition, as studied in many setting. Of the given population the health status depends on the expression of genetic traits in

* Address correspondence to this author at the Department of Pediatrics, Sindh Government Children Hospital, North Nazimabad, Karachi, Pakistan.

E-mail: sejal.neel@hotmail.com association with its several environmental aspects. In children, nutritional status and development are traditionally considered some of the most essential health status indicator. More than $60 \%$ especially in older school going children had hypolactasia, and half of them had Lactose intolerance [1]. Mostly symptoms are so vague and inconclusive that diagnosis remains a dilemma. High prevalence of lactose intolerance and mal-absorption in Asian Children and their link with high incidence of under-nutrition in our part of world needs to be investigated and understood. Lactose intolerance associated mal-absorption needs to be evaluated.

Lactase is mostly condensed in the mucosal cells of the brush border of the jejunum [2]. Lactase Insufficiency is having 
small concentration of lactose cleaving enzyme, lactase in the brush border of mucosa of small intestine. This hypolactasia causes inadequate digestion of lactose and a phenomenon, known as lactose mal-absorption or lactose mal-digestion. Lactose mal-absorption is rise in blood glucose concentration of $<1.12 \mathrm{~m}-\mathrm{mol} / \mathrm{L}$ or in breath hydrogen of $>20 \mathrm{PPM}$ after ingestion of $1 \mathrm{~g}-2 \mathrm{gm} / \mathrm{kg}$ body weight or $50 \mathrm{gm}$ of lactose [3].

According to the literature available total inability to synthesize lactase is a rare genetic disorder and is lethal. It can be managed via soya based infant formula if diagnosed early. Lactase level do not tends to increase until 3rd trimester therefore premature babies are more like to be lactose intolerant. In premature infants lactase may not be present in normal amounts in intestinal cells. Initially these cases resemble the congenital ones. However, the sensitive to milk usually disappear within a few days of birth. Because lactase activity rises relatively late in fetal life be anticipated in extremely premature infants and in some older children and adults. Approximately $40 \%$ of adult Asians are deficient in intestinal lactase. This is known as adult onset hypolactasia and is an autosomal recessive characteristic.

An estimated 826 million people as determined in 1996-1998 were malnourished out of which 792 million people live in the developing world. Nearly $54 \%$ of the mortality in young children is associated with malnutrition [4]. Alarmingly, according to the report, of UNICEF, (Progress for Children World Report 2006) In South Asian countries 27\% of children that are around 146 million are under weight, to an extent that resulting in mortality. Half of them live in India, Bangladesh and Pakistan. More than half of world's underweight children live in four nations - Bangladesh (8 million), Pakistan (8 million), China (7 million) and India (57 million). Lactase deficiency may be secondary to heavy parasite infection (mostly Giardiasis lamblia), AIDS, ionizing radiation, drugs and gastric surgery, which can cause damage to small intestine [5].

Another dimension of the problem could be lactose intolerance leading to under-nutrition that is why it is necessary to find the prevalence of the lactose intolerance. Considering this magnitude of the problem of malnutrition in children, this study may identify another contributing entity and also show its magnitude.

\section{METHODOLOGY}

This is a cross sectional study design. Children between the ages of 05 to 15 years in two selected schools of Ibrahim Hydri from Karachi were taken as research subjects. Informed consent from their parents and school administration was taken. Exclusion criteria is children who are currently ill or are on antibiotics or other medications that could alter the hydrogen breath level will be excluded from the study. Known cases of lactose intolerance will not be the part of study. Keeping in view the findings from the literature and assuming the prevalence of lactose intolerance of $50 \%$ in children of Ibrahim Hydri, at confidence level of 0.05 with an absolute precision of 0.07 our calculated sample size was at least 196. After rounding of and assuming a refusal rate of $23.5 \%$ we intended to assess a total of 242 children. But during this study 22 children did not fulfill the inclusion criteria. So the sample size turned to be 220 .

Performing Hydrogen Breath Test on children assessed prevalence of Lactose Intolerance. Principle of Breath hydrogen test is $\mathrm{H} 2$ only appears in expired air following intra-colonic bacterial fermentation of unabsorbed carbohydrate due to the deficiency of lactose enzyme. The Quintran Model 12i microlyzer is special purpose gas chromatograph, which has been designated to, means small quantities of hydrogen in expired air (alveolar) and sample in presence of trace amount of other biologically produced reducing gases.

The child ingested a load of Lactose of $2 \mathrm{gm} / \mathrm{kg}$ of body weight with a maximum of $50 \mathrm{gms}$. The breath was collected in sealed plastic containers at various intervals. The hydrogen content of the gas in the breath was measured and is reported in particle per min. (ppm). Breath air was collected in $60 \mathrm{cc}$ syringe. First sample was taken in fasting and then after giving challenge of lactose $02 \mathrm{G} / \mathrm{kg}$, subsequent samples were collected at intervals of 30, 60, 90 and 120 minutes. After the calibration the alveolar air sample collected from the Patient analyzed in Lab. WHO software "Nutri-survey" and "Anthro" calculated anthropometric measurements. NCHS growth standards were referred. They were further classified according to WHO and Gomez's classification of malnutrition and were assessed by height/age, weight/height and weight/age wise.

Calculating the proportion of children having lactose intolerance by the breath test described above assessed prevalence. Frequencies and percentages were computed for qualitative variables and quantitative variables were expressed as mean and standard deviation. Chi-square test was applied to assess the association of malnutrition with lactose intolerance. WHO and Gomez's classification of malnutrition were used to find the association. Calculations were performed with statistical software package SPSS version 13.

\section{RESULTS}

In the sample size of 220 children, 145 (66\%) were males and $75(34 \%)$ were female. Mean age was 9.5 years with a standard deviation of 1.7 . Mean weight was $27.4 \mathrm{~kg}$ with a standard deviation of 7 . Mean height was $134.8 \mathrm{~cm}$ with a standard deviation of 12.1 . Mean BMI was $14.8 \mathrm{~kg} / \mathrm{m} 2$ with a SD of 1.7 (Table 1). 
Table 1. Demographic Variables.

\begin{tabular}{|l|l|}
\hline Demographic Variables & $\begin{array}{l}\text { Mean } \pm \text { Standard Deviation } \\
\text { or Frequency (\%) }\end{array}$ \\
\hline Age (in years) & $9.5 \pm 1.7$ \\
\hline Weight $(\mathrm{kg})$ & $27.4 \pm 7$ \\
\hline Height $(\mathrm{cm})$ & $134.8 \pm 12.1$ \\
\hline BMI $(\mathrm{kg} / \mathrm{m} 2)$ & $14.8 \pm 1.7$ \\
\hline Gender & $145(66)$ \\
\hline Male & $75(34)$ \\
\hline Female &
\end{tabular}

Peak prevalence of Lactose intolerance (HBT positive) was amongst the group of children age greater than 11 years that is $36.4 \%$. 10(29\%) children were positive between 10 to 11
This study shows that $68(31 \%)$ subjects were positive and $152(69 \%)$ negative for HBT in-group of 220 asymptomatic children (Fig. 1).

\section{Hydrogen Breath Test}

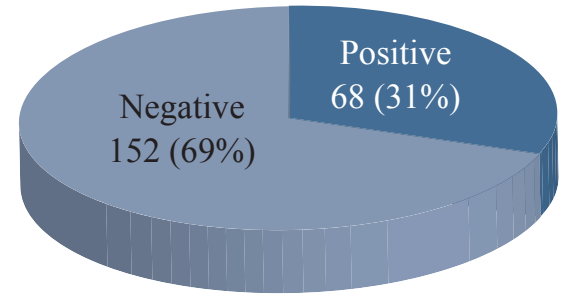

Fig. (1). Prevalence of Lactose Intolerance.

years, $8(18 \%)$ between 8 to 9 years, and $9(33 \%)$ were less than 8 years. Lowest numbers of children with lactose intolerance was found in age of 9 to 10 years (Table 2).

Table 2. Age Distribution.

\begin{tabular}{|c|c|c|c|}
\hline \multicolumn{2}{|c|}{} & \multicolumn{2}{c|}{ Hydrogen Breath Test } \\
\hline Age Groups & Total & Positive & Negative \\
\hline$<\mathbf{8}$ years & $27(12.3 \%)$ & $9(33.3 \%)$ & $18(66.7 \%)$ \\
\hline $\mathbf{8 - 9}$ years & $81(36.8 \%)$ & $29(35.8 \%)$ & $52(64.2 \%)$ \\
\hline $\mathbf{9 . 1}$ - 10 years & $44(20 \%)$ & $8(18.2 \%)$ & $36(81.8 \%)$ \\
\hline $\mathbf{1 0 . 1}$ - 11 years & $35(15.9 \%)$ & $10(28.6 \%)$ & $25(71.4 \%)$ \\
\hline$>$ 11 years & $33(15 \%)$ & $12(36.4 \%)$ & $21(63.6 \%)$ \\
\hline Total & $\mathbf{2 2 0}$ & $\mathbf{6 8}$ & $\mathbf{1 5 2}$ \\
\hline
\end{tabular}

Anthropometrics of children were also observed on percentile charts by Height, which shows that $11.8 \%$ lies below the 5 th percentile and amongst them $46 \%$ were intolerant and 54\% were tolerant, $19.5 \%$ were at 95 th percentile and above and $21 \%$ amongst them were intolerant and $79 \%$ were tolerant. Bars in graph shows the percentages of tolerant group increases and percentages of intolerant group decreases as we observe it from 5th to 90th percentile (Fig. 2). According to WHO classification, stunted and normal height children were $27.3 \%$ and $72.7 \%$ respectively. Among normal height children, $117(73.1 \%$ ) children were found tolerant to lactose, which was higher than stunted group in which $35(58.3 \%)$ children were lactose tolerant. In stunted height group, $25(41.7 \%)$ children were intolerant to lactose as compared to normal height group in which $43(26.9 \%)$ lactose intolerant children were observed. The difference of tolerant children between stunted and normal height was statistically significant $(\mathrm{p}=0.034)($ Table 3$)$.
Anthropometrics of children were also observed on percentile charts by Weight shows that $17.3 \%$ were below the 5th percentile, amongst them $39.5 \%$ were intolerant and $60.5 \%$ were tolerant. At the 95 th percentile and above there were $4.1 \%$ children and amongst them $33 \%$ were intolerant and $67 \%$ were tolerant (Fig. 3). According to Gomez's classification $57(25.9 \%)$ children were underweight and among them, 21(36.8\%) were intolerant which was higher than normal weight group that had $47(28.8 \%)$ intolerant children. 116(71.2\%) children showed negative test result for HBT, which was higher than underweight in which 36 $(63.2 \%)$ children were intolerant to lactose. However, this difference was not statistically significant between the two groups $(\mathrm{p}=0.26)($ Table 3$)$.

Anthropometrics were analyzed according to Weight by Height that showed $51 \%$ wasted children, amongst them $26.2 \%$ were intolerant and $73.8 \%$ were tolerant in comparison of $37.7 \%$ intolerant and $62.3 \%$ tolerant in well-nourished 
group. Positive and negative HBT cases among wasted and normal children did not show any significant difference $(\mathrm{p}=$ 0.125) (Table 3). In this analysis only 157 subjects were included because of the limitation of the "Nutrisurvey" (software).
Sex distribution shows that $34 \%$ were female and $66 \%$ were male, there was no significant difference amongst tolerant and intolerant in the both sexes $(\mathrm{p}=0.90)$ (Table 3$)$.

Table 3. Comparison of Gender, Height/Age, Weight/Age and Weight/Height among Children with Positive \& Negative HBT.

\begin{tabular}{|l|c|c|c|c|}
\hline & Positive & Negative & Total & \\
\hline Gender & & & & \\
\hline Male & $45(66.18 \%)$ & $100(65.79 \%)$ & $145(66 \%)$ & 0.900 \\
\hline Female & $23(33.82 \%)$ & $52(34.21 \%)$ & $75(34 \%)$ & 220 \\
\hline Total & 68 & 152 & - \\
\hline
\end{tabular}

\section{Classification of Height/Age}

\begin{tabular}{|l|c|c|c|c|}
\hline$>95 \%$ of Median (Normal Height) & $43(26.9 \%)$ & $117(73.1 \%)$ & $160(72.7 \%)$ & $0.034^{*}$ \\
\hline$\leq 95 \%$ of Median (Stunted Height) & $25(41.7 \%)$ & $35(58.3 \%)$ & $60(27.3 \%)$ & 220 \\
\hline Total & 68 & 152 & - \\
\hline
\end{tabular}

\section{Gomez's Classification for Wt/Age}

\begin{tabular}{|l|c|c|c|c|}
\hline$>80 \%$ of Median (Normal Weight) & $47(28.8 \%)$ & $116(71.2 \%)$ & $163(74.1 \%)$ & 0.260 \\
\hline$\leq 80 \%$ of Median (Underweight) & $21(36.8 \%)$ & $36(63.2 \%)$ & $57(25.9 \%)$ & 220 \\
\hline Total & 68 & 152 & - \\
\hline
\end{tabular}

\section{Classification of $\mathrm{Wt} / \mathrm{Ht}$}

\begin{tabular}{|l|c|c|c|c|}
\hline$\geq 90 \%$ of Median & $29(37.7 \%)$ & $48(62.3 \%)$ & $77(49 \%)$ & 0.125 \\
\hline$<90 \%$ of Median & $21(26.2 \%)$ & $59(73.8 \%)$ & $80(51 \%)$ & 157 \\
\hline
\end{tabular}

\section{*P-value $<0.05$ was taken as significant.}

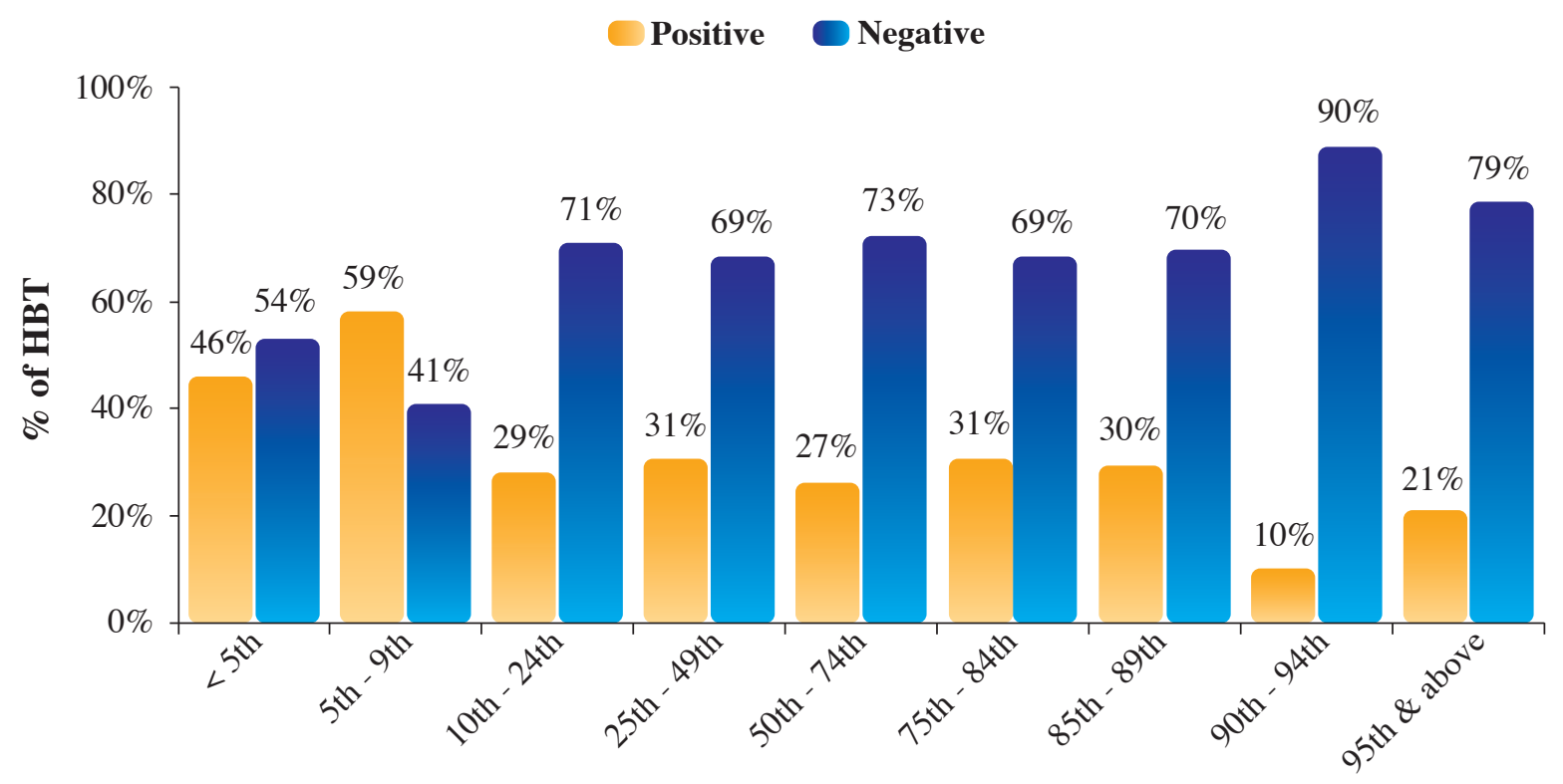

Fig. (2). Height/Age Percentile Groups. 


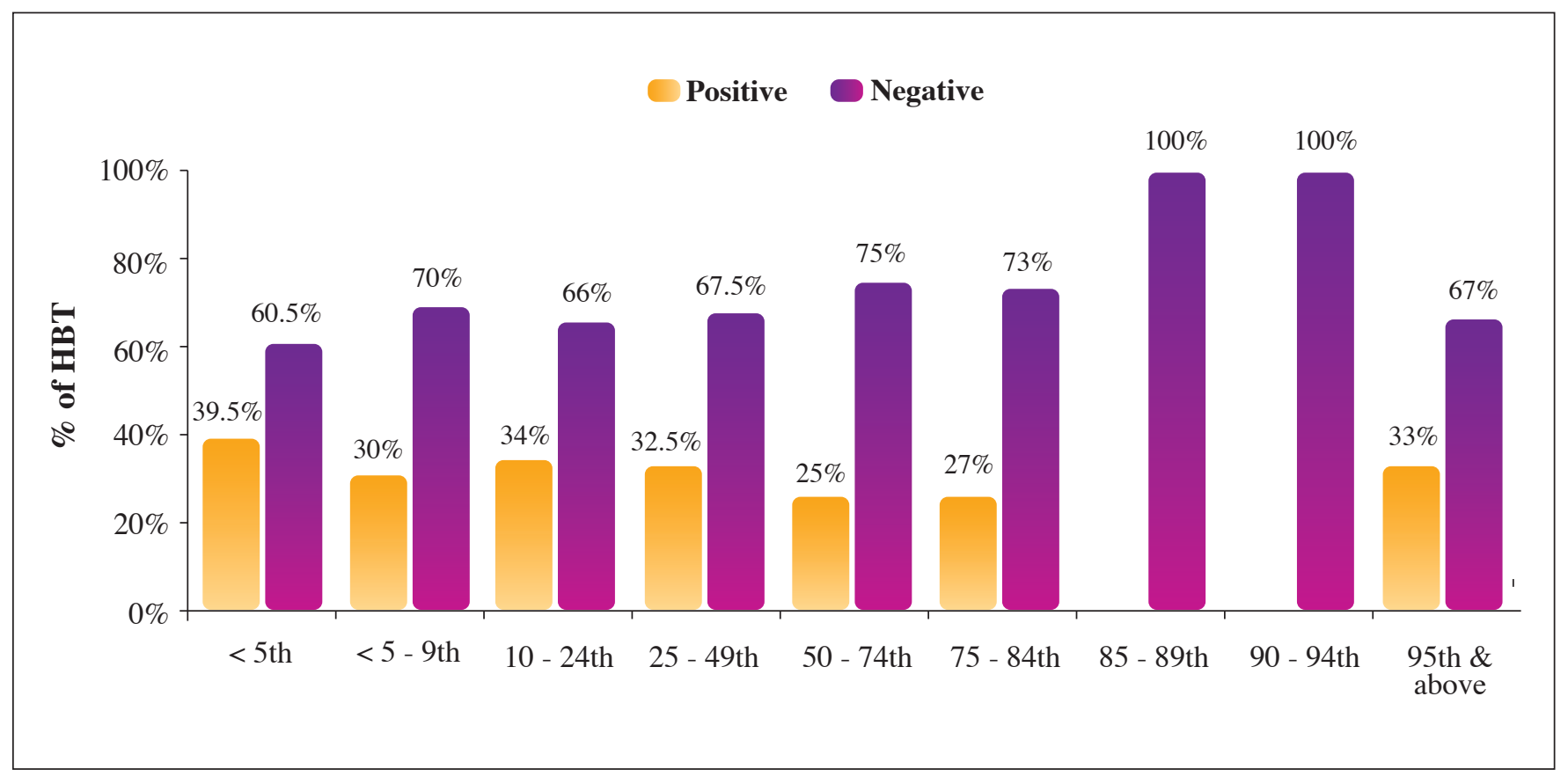

Fig. (3). Weight/Age Percentile Range.

\section{DISCUSSION}

This study showed 31 percent prevalence of Lactose intolerance in a asymptomatic 220 children. This may be an isolated result of that particular area, but this is comparable with the other studies in literature. Tendon and Joshi carried a multi-centered study in North and South India and found 66.6\% incidence in Trivandrum and Pandacherry (South India) and $27.4 \%$ in New Delhi (North India) [1]. Result of my study shows $31 \%$ prevalence of Lactose Intolerance, which is comparable to the prevalence as in Northern India. Other studies in Asia, like Bangladesh had 80\% prevalence in children over 36 month of age as studied by Brown KH, et al. [6]. A comparison of Pakistani with Middle East children shows Jewish children in Israel to be twice as affected (61\%) as our children [7]. De Villiers FP from the Johannesburg published his work in South African medical journal reported saying that lactose intolerance in $85.9 \%$ of children is seen after the age of 3 years [8]. The established age incidence of different studies in this regard does not show any particular age pattern.

In our study peak prevalence of Lactose intolerance (HBT positive) was amongst the group of more than 11 years of age children that is $36.4 \%$. The highest number of Lactose Intolerance was found in oldest age group that is more than 11 years and 33\% in lowest age group, but it does not show any gradual increase in number as the age increases. Age limit in this study was between 5 and 15 years therefore we cannot estimate prevalence under five years and over fifteen years of age.
Bejanones did not found lactose mal-absorption in children less than three years. He found highest rate in 6 to 16 years of age group [7]. Yang yham and Cui H investigated in Chinese children and they found the highest prevalence in 7 to 13 years but they did not describe it as increasing with age [9]. Age occurrences in Bejanones and Yang yham's work is comparable with this study and did not show any gradual increased pattern with age but showed highest prevalence in older age group and lowest in smaller age group. On the other hand Sadre M. and Karbasi K. in Iran found that prevalence of lactose mal-absorption increased with age [10]. Brown $\mathrm{KH}$, et al. in Bangladesh diagnosed LI in more than $80 \%$ of Children over 36 months of age but none of the children under 6 months of age but they too did not describe any gradual increase with age [6]. Cabr M. and Beheiry F. observed gradual increase in Lactose Intolerance as age increased in Egyptian children. They found $12 \%$ in age group of 6 month to 2 years, $32 \%$ in age group of 5 to 9 years and $80 \%$ in 9 to 12 years of age group [11].

According to the WHO classification of Malnutrition, 27.3\% of children in this group of population were stunted. Stunted group had $42 \%$ intolerant and $58 \%$ tolerant Children. When we observed the percentage of intolerant children in stunted and normal height groups of children, we did not find any significant difference. But when tolerant group (Negative HBT), was observed for the difference in stunted and normal height group children was statistically significant $(\mathrm{P}$ value $=$ 0.034) (Table 3).

When frequency of lactose intolerance and tolerance was assessed in term of weight for age on Standard NCHS charts, 
it showed that who had lower percentile (underweight group) for weight/age were more lactose intolerance compared to those who had higher percentile (well-nourished group) for weight for age. Contrarily, when looked for tolerant children, their percentage on higher percentile were more in compared to those who were at lower percentile for weight /age (Fig. 3). But the data was not statically significant.

Rosado JI's study also supports the idea as he concludes in his study that the undernourished group had a higher incidence of both lactose mal-digestion and lactose intolerance. Rosado JI studied in Mexico and strongly suggests that undernourishment is accompanied always or almost always by lactose intolerance [12]. Some scientist and researchers disagree with this and see no relationship between LI and malnutrition, NW Solomons, B Torun, observe the effect of dietary lactose on the early recovery from protein-energy malnutrition and Clinical and anthropometric indices. They found that the routine reduction of lactose content from a milk-based diet for severe protein-energy malnutrition offers no advantages [11].

Leslie J, MacLean WC. Jr, Graham GG, observed that there were decreasing proportions of positive responders with increasing age. No difference in response attributable to type or severity of malnutrition was found. The previous data was compared with his data from children of same community who were not under weight and encouraged that acute malnutrition accelerates the permanent decline of lactase activity normally expected later in life [13].

In our study, when specifically asked for history of abdominal pain $58.6 \%$ answered in affirmative and $41.4 \%$ said no in response. Boeyee in Malaya and Herman MM. and Brummer RJ. in Netherland found gastrointestinal symptoms high in lactose deficient children. Our study shows that $58.6 \%$ had a history of vague abdominal pain Out of those who had abdominal pain $61 \%$ were tested as lactose intolerance and $57 \%$ as lactose tolerant. on the other hand amongst children who had no history abdominal pain have $38.2 \%$ intolerant (HBT positive) and $42.8 \%$ tolerant (HBT negative), but their difference was not statistically significant. Finding of this study co-relate with the result of Boeyee in Malaysia and Abrunmer RJ. in Netherlands where they found that lactose intolerance does not always present with symptoms [14].

Children with severe protein-energy malnutrition commonly have a reduced activity of intestinal lactase, the enzyme responsible for the digestion of lactose $[15,16]$, and it has been suggested that feeding this disaccharide can retard nutritional recovery [17]. Secondary lactase deficiency can present at any age but is more common in infancy [18, 19]. This contrasts with the risks in normal children as demonstrated by Gabr and colleagues in Egypt: $12 \%$ in the age group 6 months to 2 years, $32 \%$ in the age group $2-5$ years, $32 \%$ in the age group $5-9$ years, and $80 \%$ in the age group 9-12 years [20].

To fulfill the international commitment and decrease the risk of children dying by under nutrition and to decrease the percentage of underweight children by half we need a comprehensive strategic policies based on scientific evidence. Changing in food habit according to our natured inherit ant might ease our sufferings. National program for school nutrition program which are always encourages the milk supplements may needs changes in their policy making when they were framing the school nutrition program. In most of the cases elimination of milk totally from the diet may not be required. Stopping ingestion of milk as a beverage is important.

\section{CONCLUSION}

In this study high prevalence of lactose intolerance was documented, so there is a need of newer recommendation to reduce the quantity of milk in daily diet and substituted by other food products with equal nutritive value. Also food items with intrinsic lactase activity can be used to overcome the problem.

As this is a descriptive study, further extensive research is required to know the true prevalence of Lactose Intolerance in Pakistani children and its effect on growth.

We could not fully link up the lactose intolerance and under-nutrition, but we can recommend on the bases of finding in this research that whenever new policies of combating malnutrition were framed, use of milk in supplementation program should be used with caution.

\section{CONFLICT OF INTEREST}

Declared none.

\section{ACKNOWLEDGEMENTS}

Declared none.

\section{REFERENCES}

[1] Tandon RK, Joshi YK, Singh DS, et al. Lactose intolerance in North and South Indians. Am J Clin Nutr 1981; 34(5): 943-6. DOI: 10.1093/ajen/34.5.943

[2] Buller HA, Grand RJ. Lactose intolerance. Ann Rev Med 1990; 41: 141-8.

DOI: 10.1146/annurev.me.41.020190.001041

[3] Bayless TM. Lactose malabsorption, milk intolerance, and symptom awareness in adults. In: Paige DM, Bayless TM, Eds. Lactose digestion: Clinical and Nutritional Implications. Baltimore: Johns Hopkins University Press 1981; pp. 117-23.

[4] Johnson JD. The regional and ethnic distribution of lactose malabsorption. Adaptive and genetic hypotheses. In: Paige DM, Bayless TM, Eds. Lactose Digestion: Clinical and nutritional implications. Baltimore: Johns Hopkins University 
Press 1981; pp. 11-22.

[5] Castiglia PT. Lactose intolerance. J Pediatr Health Care 1994; 8(1): 36-8. DOI: 10.1016/0891-5245(94)90101-5

[6] Brown KH, Parry L, Khatun M, et al. Lactose malabsorption in Bangladeshi village children: Relation with age, history of recent diarrhea, nutritional status, and breast feeding. Am J Clin Nutr 1979; 32(9): 1962-9. DOI: 10.1093/ajcn/32.9.1962

[7] Bujanover Y, Katz A, Peled Y, et al. Lactose malabsorption in Israeli children. Isr J Med Sci 1985; 21(1): 32-5.

[8] de Villiers FP. Relationship between milk lactose tolerance and body mass in teenage Tswana schoolchildren. South Afr Med J 1988; 74(10): 499-501.

DOI: $10.1016 / \mathrm{S} 0031-9406(10) 63383-4$

[9] Newcomer AD, Thomas PJ, McGill DB, et al. Lactase deficiency: A common genetic trait of the American Indian. Gastroenterology 1977; 72(2): 234-7.

[10] Hermans MM, Brummer RJ, Ruijgers AM, et al. The relationship between lactose tolerance test results and symptoms of lactose intolerance. Am J Gastroenterol 1997; 92(6): 981-4.

[11] Solomons NW, García-Ibáñez R, Aycinena P, et al. Lactose intolerance in protein-energy malnutrition: A clinical case study and family study using a hydrogen (H2) breath-analysis test for carbohydrate malabsorption. Arq Gastroenterol 1979; 16(3): 137-45.

[12] Rosado JL. Importance of nutritional status in digestion capacity and lactose tolerance. Rev Invest Clin 1996; 48 (Suppl): 45-50.
[13] Leslie J, MacLean WC, Graham GG. Effect of an episode of severe malnutrition and age on lactose absorption by recovered infants and children. Am J Clin Nutr 1979; 32(5): 971-4. DOI: $10.1093 / \mathrm{ajcn} / 32.5 .971$

[14] Boey CC. Lactase deficiency among Malaysian children with recurrent abdominal pain. J Paediatr Child Health 2001; 37(2): 157-60. DOI: 10.1046/j.1440-1754.2001.00622.x

[15] James WPT. Jejunal disaccharide activities in children with marasmus and with kwashiorkor. Arch Dis Child 1971; 46: 218-20. DOI: 10.1136/adc.46.246.218

[16] Bowie MD, Brinkman GL, Hansen JDL. Acquired disaccharide intolerance in malnutrition. J Pediatr 1965; 66: 1083-91. DOI: $10.1016 / \mathrm{S} 0022-3476(65) 80095-6$

[17] Lifshitz F. Acquired carbohydrate intolerance in children: Clinical manifestations and therapeutic recommendations. USA: The Johns Hopkins University Press 1981; pp. 80-90.

[18] Melvin BH. Lactose intolerance in infants, children, and adolescents. Pediatrics 2006; 118(3): 1279-86.

DOI: $10.1542 /$ peds.2006-1721

[19] Ozmert E, Yurdakok K, Aslan D, et al. Clinical characteristics of transient glucose intolerance during acute diarrhoea. Acta Paediatr 1999; 88: 1071-3. DOI: 10.1111/j.1651-2227.1999.tb00990.x

[20] Gabr M, El-Beheiry F, Soliman AA, et al. Lactose intolerance in normal Egyptian infants and children and in protein calorie malnutrition. Gaz Egypt Paediatr Assoc 1977; 26(1): 27-33. 